\title{
Removal of methyl orange (MO) using carbon quantum dots (CQDs) derived from watermelon rinds
}

\author{
${ }^{1}$ U.R.Ramzilah, ${ }^{2}$ A.Aziz \\ ${ }^{1,2}$ Faculty of Engineering Technology, University Malaysia Pahang, 26300, Kuantan, Pahang, Malaysia \\ *Email: azrinaaziz@ump.edu.my
}

\begin{abstract}
In this study, carbon quantum dots (CQDs) was prepared via a facile hydrothermal method. The objective for this study is to assess the performance of CQDs in photocatalytic degradation activity of methyl orange (MO) under artificial visible light source. For that reason, the prepared photocatalyst undergo further characterization by scanning electron microscope (SEM), energy dispersive X-ray spectroscope (EDX) and UV- Vis spectrophotometer (UV-VIS) to verify the morphology structure of the photocatalyst, elemental composition as well as the absorbance intensity, respectively. The results indicate that the prepared photocatalyst possess irregular porous shape with nanometre $(\mathrm{nm})$ dimensions that can escalate the surface area for photocatalytic degradation activity. The elements of the photocatalyst mainly consist of carbon and oxygen as the major constituents in which necessary for photocatalytic activity with intense peak of absorbance intensity. The prepared CQDs also shows an excellent photocatalytic performance over the MO with degradation rate of $68.9 \%$ within 120 minutes.
\end{abstract}

Indexed Terms- CQDs, hydrothermal, methyl orange, photocatalytic degradation, watermelon rinds

\section{INTRODUCTION}

The development of utilization of synthetic dyes contributes many negative impacts on human wellbeing as well as the aquatic organisms when directly dispense out to the environment. The dyes comprise of toxic and complex components, which can influence unfavorable color changes of the water due to their slow degradation rate. Furthermore, the unpleasant effect not only from aesthetic point of view, yet in addition from decreasing in sunlight penetration that reducing the activity of photosynthesis [1,2]. Dyes are widely used in industries like textile, food, cosmetics, plastics, printings and paper to color their products. Annually, there are about 100, 000 types of synthetic dyes with more than 70,000 tons of production from the associated industries in which 15-20\% of it lost and carried away as wastewater [2,3]. Methyl orange $\left(\mathrm{C}_{14} \mathrm{H}_{14} \mathrm{~N}_{3} \mathrm{NaO}_{3} \mathrm{~S}\right)$ is one of the anionic dyes that extensively used in the associated industries and concerning to its amount and harmful effect, it is important to treat the dye components before discharging into the water body [2-4] .

One of the promising method in handling the dye wastewater other than reverse osmosis, electrocoagulation, electrochemical oxidation, membrane filtration, ozonation and adsorption is photocatalysis. Photocatalysis is a process where light and catalyst are simultaneously utilized in order to support and speed up the chemical reaction [5]. Photocatalysis process has showing significant advantages over the available competing process nowadays in terms of complete mineralization, no waste disposal, low cost and necessity need of mild temperature and pressure condition [5,6]. In this process, when photocatalyst is irradiated with sufficient energy corresponding to the band gap, electron transfer may occur. The capability of electron transfers to occur within the photocatalyst makes it possible to be utilized as a trigger to start redox reaction with the substrate. This redox reaction take action on the photodegradation of organic compounds inclusive the dye molecules and convert them into basic compounds such as $\mathrm{CO}_{2}, \mathrm{H}_{2} \mathrm{O}$ and mineral acids [4,5]. Over the past decades, CQDs turned up to be as an attractive materials for photocatalysis applications since it is first discovered in 2004, that firstly disclosed by accident when refining carbon nanotubes 
fabricated by arc- discharge method [7,8]. CQDs which embarked their way as a class of carbonbased nanomaterials over the past decade can be seen have quasi- spherical in shape, discrete and less than $10 \mathrm{~nm}$ in size. Obviously, due to their unique characteristics they had attracted huge interest in many fields such as bioimaging, biosensing, electrocatalysis, photocatalysis and nanomedicine $[9,10]$. CQDs, primarily consist of amorphous carbon together with nanocrystalline regions of $\mathrm{sp}^{2}$-hybridized graphitic carbon. Recognizably from many other carbon nanomaterials like carbon nanotubes, graphene oxide and graphene quantum dots, CQDs can be synthesized effortlessly and economically using low- cost and sustainable source of biomass such as watermelon rinds, hair and even cow manure [11]. As a result, variety of synthesizing approaches for the preparation of CQDs were developed. In past few years, several methods involve in the synthesis of CQDs including laser ablation [12,13], arc discharge [14], pyrolysis [15], hydrothermal treatment $[9,16]$ and microwave irradiation [17-19]. There are several advantages in using the laser ablation, arc discharge, pyrolysis and microwave irradiation methods which is rapid and effective process with scalable and tunable surface states, size- controllable as well as cost effective [8]. Regardless of all that, although the above mentioned procedures excluding the hydrothermal, were successful in producing the CQDs, yet they clearly suffer some difficulties because most of the methods required tedious process with several steps, harsh chemical reaction, complex instrumental setup, limited spectral efficiency and low product yield which restrict their wide applications [20,21]. At the same time, even though hydrothermal treatment reported has poor control over size which means that the produced CQDs are vary in size, however in green perspective hydrothermal treatment is consider as a non-toxic route in preparation of CQDs which is good to the environment as well as low cost production [8]. Using this technique, large-scale production is possible and reaction conditions such as time and temperature are adjustable [22].

Since discovery, CQDs outbreak many fascinating qualities which settle them as potential replacement for conventional semiconductor quantum dots in enhancing photocatalytic degradation. Mainly, they possess a strong photoluminescence (PL) which can be tuned and controlled by the nanoparticles' size. The formation of thin insulating capping layer by surface passivation can assist to further improve the fluorescence intensity of the CQDs. Moreover, since CQDs are carbon based materials, they may as well own oxygenated groups, in which their surfaces can be easily functionalized with the organic molecules. Thus, various heteroatoms can be introducing to them and be useful in tailoring their wavelength emission and consequently their applicability [23]. CQDs are highly soluble in $\mathrm{H}_{2} \mathrm{O}$ with desirable and adjustable hydrophilicity. CQDs possess two additional and vital characteristics; low cytotoxicity and excellent biocompatibility that exhibit them superior compared to conventional semiconducting quantum dots and equipped them with the potential of biological use $[8,16,23]$.

The utilization of watermelon rinds (WMR) acquire from the agricultural wastes as carbon source has aroused the interest and enthusiasm of researchers as conducted studies by Han and coworkers [15],Jawad et.al [24] and Jimoh et.al [25] because it offers both low cost of carbon source and address the agricultural waste problem altogether. Watermelon (Citrullus lanatus) being an exceptionally well known and notable as a non-seasonal fruit in Malaysia that categorized as a major fruits by the Ministry of Agriculture and Agro-based Industry, with an average of annual production rate around 154,416 tones [24]. The freshening and thirst- quenching red flesh with pleasant smell and taste make the watermelon very popular in making juice and even desserts. In spite of its popularity, the outer WMR is treated as waste that not valuable in daily life. WMR contain protein, carotenoids, cellulose, citrulline, pectin and flavonoids [24,26,27] with abundant of various surface functional groups such as carboxyl, hydroxyl and amine that can easily draw the cationic ions and render them as a potential candidate in water and wastewater treatment process [24]. In addition, because of antioxidant activity of citrulline it produce hydroxyl radicals strong oxidizing agent which is suitable for degradation process[28]. Moreover, many researchers speculate that flavonoids in the WMR are potential 
scavenger of hydroxyl that can be used for photocatalytic activity [24,29,30]. In several reported studies, WMR were used as adsorbent in removal of dyes using the adsorption process [24,31,32]. To date, it is reported that only watermelon juice has been used as carbon precursor to synthesis the CQDs. However, for the evaluation of CQDs performance in photocatalytic activity, the application of CQDs as solely catalyst is still scant and many reported studies shows the application of CQDs in bioimaging, bio-sensing, chemical sensing as well as printing $[19,22]$.

The purpose of this present study is to explore the potentiality of CQDs in photocatalytic degradation for color removal of aqueous solution containing MO dye under artificial visible light. This study will start with the production routes of CQDs with adjustable condition of the hydrothermal treatment, followed by a brief look on the crystalline and electronic structure of the photocatalyst as well as the photocatalyst optical properties. Then, the vital contribution of CQDs as an active component in artificial visible light photocatalysis will be analyzed in detail, based on the properties that have been examined.

\section{MATERIALS AND METHODS}

\subsection{Materials}

Watermelon rinds were collected from Universiti Malaysia Pahang (UMP) Cafeteria and used as source of carbon. Ethanol $\left(\mathrm{C}_{2} \mathrm{H}_{6} \mathrm{O}, 95 \%\right)$, dichloromethane $\left(\mathrm{CH}_{2} \mathrm{Cl}_{2}, 99.8 \%\right)$ and acetone $\left[\left(\mathrm{CH}_{3}\right)_{2} \mathrm{CO}\right.$, 99\%] were purchased from Sigma Aldrich Chemical Co. MO dye $\left(\mathrm{C}_{14} \mathrm{H}_{14} \mathrm{~N}_{3} \mathrm{NaO}_{3} \mathrm{~S}\right)$ was obtained from the UMP lab and used as a target pollutant in degradation activity. All the purchased chemicals were analytical grade and used without further purification. Distilled water was used for sample preparation.

\subsection{Preparation of CQDs}

CQDs was synthesized using the mixture of fruit waste and ethanol via hydrothermal treatment. Watermelon rinds were collected from UMP Cafeteria. The watermelon rinds then washed thoroughly with distilled water and drained to remove excess water. The watermelon rinds were cut into smaller pieces and grinded into fine paste using a blender and filter using $0.5 \mathrm{~mm}$ sieve. $40 \mathrm{ml}$ of watermelon rinds juice was mixed with $30 \mathrm{ml}$ ethanol under vigorous stirring for 5 minutes. Then, the mixture was poured into Teflon-lined-stainless steel autoclave and heated at constant temperature of $120^{\circ} \mathrm{C}$ for 150 minutes in oven. The resulted dark brown solution is washed with dichloromethane $\left(\mathrm{CH}_{2} \mathrm{Cl}_{2}\right)$ and centrifuged at $3000 \mathrm{rpm}$ for separation of less fluorescence deposit. Excess acetone $\left(\left(\mathrm{CH}_{3}\right)_{2} \mathrm{CO}\right)$ is added to upper parts of solution and centrifuged at $6000 \mathrm{rpm}$ to obtain highly fluorescent CQDs of size ranging from $1.5-4.5 \mathrm{~nm}[20]$.

\subsection{Characterization}

The morphologies of samples were examined by a Scanning Electron Microscope (SEM, HITACHI TABLETOP TM3030 PLUS). The images were taken at an accelerating voltage of $15 \mathrm{kV}$. The energy dispersive X-ray spectroscope (EDX) (Hitachi Model, TM3030 Plus) were analyzed to determine the occurrences of the important elements present in the prepared samples. The samples were acquired at 30 seconds acquisition time with $15 \mathrm{kV}$ of accelerating voltage. The visible light absorption spectrum (300-900 nm) of the prepared photocatalyst was certified by UV-Vis analysis (UV- 2600, SHIMADZU) and quartz cell (10 $\mathrm{mm}$ path length).

\subsection{Measurement of photocatalytic activity \\ 2.4.1 Preparation of MO stock solution}


The MO with an acidic $\mathrm{pH}$ (3.1- 4.4) presented an intense orange yellow. MO solution was prepared by diluted $1 \mathrm{~g}$ of MO powder in $1000 \mathrm{~mL}$ distilled water. The mixture was kept under magnetic stirring until the powder completely dissolved and later put in refrigerator until further used.

\subsubsection{Degradation of $M O$}

The photocatalytic activity was carried out by a self-made reactor equipped with a Halogen lamp (500 W) with $<420 \mathrm{~nm}$ UV cut- off filter to stimulate the irradiation and light intensity. The photocatalytic activity of CQDs were conducted by evaluating the removal rate of methyl orange (MO). $0.1 \mathrm{~g}$ of CQDs was prepared and dissolved in $100 \mathrm{~mL}$ of MO solution $(5 \mathrm{ppm})$. This mixture was kept under magnetic stirring for 1 hour in dark to achieve the adsorption equilibrium before light irradiation. After 1 hour, $3 \mathrm{ml}$ of the solution was taken out to evaluate the concentration. After that, $500 \mathrm{~W}$ halogen lamp that positioned above $11 \mathrm{~cm}$ from the surface of the MO solution was switch on $[9,12,33]$. The reaction was performed for $120 \mathrm{~min}$ and the solutions were collected for every $20 \mathrm{~min}$. The absorbance for both solutions were determined by measure out the absorbance using a Uv-Vis Spectrophotometer (UV-1800, SHIMADZU) in the range between $200 \mathrm{~nm}$ to $1100 \mathrm{~nm}$. The degradation rate of dyes can be calculated using the following equation below:

$$
\text { Degradation rate, } \%=\frac{C_{\mathrm{o}}-C}{C_{\mathrm{o}}} \times 100 \%
$$

Where,

Co $=$ Initial concentration of pollutant

$C=$ Final concentration of pollutant

\section{RESULTS AND DISCUSSION}

\subsection{CQDs Characterization}

\subsubsection{SEM Analysis}

The identification of the structure and morphology of CQDs was carried out through SEM. As depicted in Figure 1, based on the SEM analysis of the CQDs that synthesized using hydrothermal treatment, revealed that nanostructured of CQDs was not fully dispersed in water and the agglomeration occur due to the long period of storage before analysis was carried out. This causes the formation of irregular porous shapes of CQD dots with nanometer dimension of particles size. However, the condition was not retain after sonication process. Sonication process is conducted for evenly dispersing the nanoparticles in liquid to get a better result of the nanoparticles structure. At the same time, since the size of the CQDs is very small, the surface and structure of CQDs can be confirmed using TEM analysis. However, the condition was not retain after sonication process. 


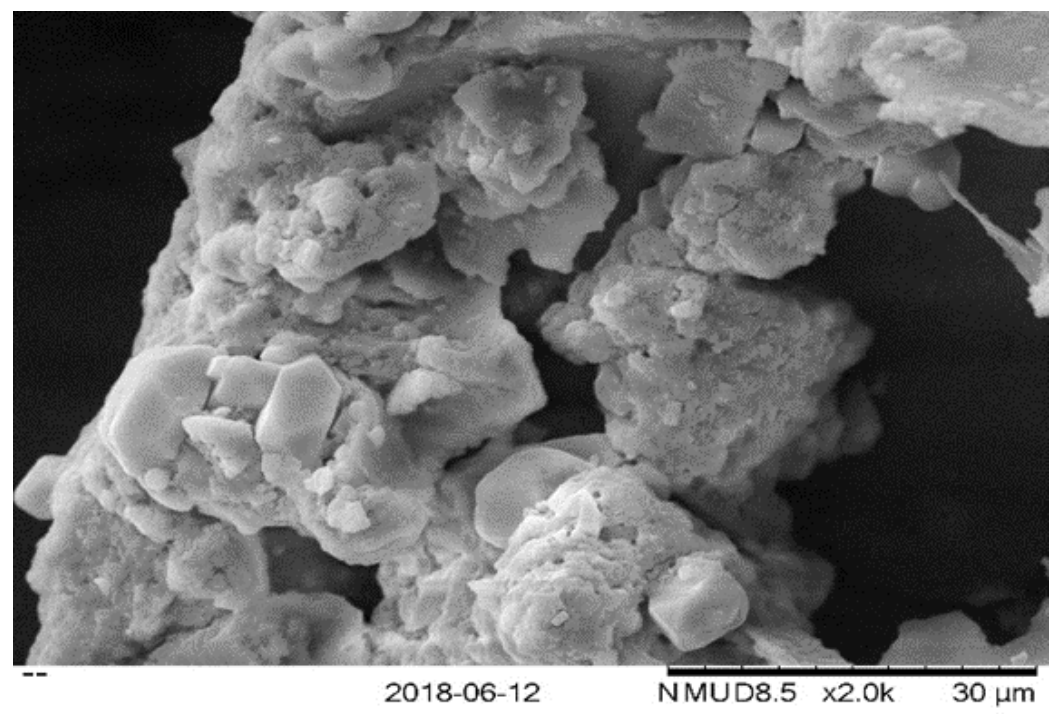

Figure 1: Image of CQDs from SEM analysis

\subsubsection{EDX Analysis}

At the same time, EDX spectrum of CQDs that illustrated in Figure 2, unveil the overall elements that presented in CQDs. They consist of $\mathrm{C}, \mathrm{O}, \mathrm{Na}, \mathrm{K}, \mathrm{Cl}$ and $\mathrm{Au}$. Each peak produced correspond to a particular element present in CQDs and was distributed during the preparation of the sample. The primary constituents of the CQDs photocatalyst comprise of C (51.57 wt. \%) and $\mathrm{O}(34.50 \mathrm{wt} . \%)$ that can be observed clearly in it which also indicating the presence of oxygenic groups such as carboxyl, hydroxyl or carboxyl which is correspond to the distribution of surface functional group of CQDs through XPS analysis. The occurrences of these elements is corresponding with study carried out by Niranjan and Bibekananda using banana juice as the carbon precursor. The value is slightly higher which is 63.39:35.69 and 70.07:29.61 of $\mathrm{C}$ to $\mathrm{O}$ ratios respectively [34]. This result also shows consistency with the previous reported studies [35-38]. The existence of these oxygenic group is expected to enhance the photocatalytic activity. At the same time, hydrothermal treatment that used as the preparation method to produce CQDs revealed that with mild temperature process, can stabilize the surface of CQDs thus facilitates their further functionalization and simplifies the application involved [7]. Meanwhile, the minority elements of the CQDs photocatalyst include $\mathrm{Na}, \mathrm{K}, \mathrm{Cl}$ and $\mathrm{Au}$ which are less than $10 \mathrm{wt} \%$. 


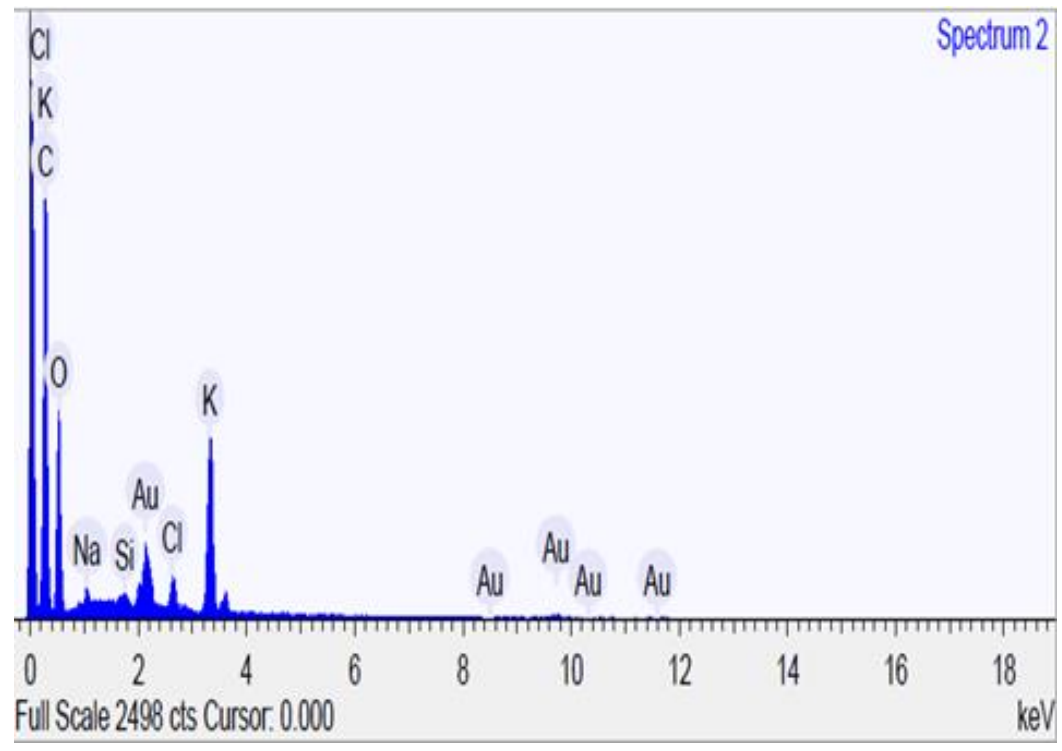

Figure 2: EDX image of CQDs

\subsubsection{UV-VIS Analysis}

The remarkable optical properties of CQDs are viewed as one of the essential factor that will influence the uses of CQDs. The Uv-Vis absorption spectrum of CQDs solution in the range of 300nm to $900 \mathrm{~nm}$ was exhibited in the Figure 3, which display only one intense absorption peak in the UV region at about $318 \mathrm{~nm}$, which correlated to $\mathrm{n}-\pi^{*}$ transitions of $\mathrm{C}=\mathrm{O}$ bonds in CQDs with a tail elongate to the visible range and all the result are in agreement with the previously reported studies $[8,39,40]$. At the same time, since one of the beneficial roles of CQDs is extending the optical absorption range of photocatalyst, this optical characteristic lead to bandgap narrowing of the semiconductor when incorporate with CQDs owing to the chemical bonding that will be formed between the semiconductor and CQDs which in result can extend the light absorption range in enhancing photocatalytic degradation.

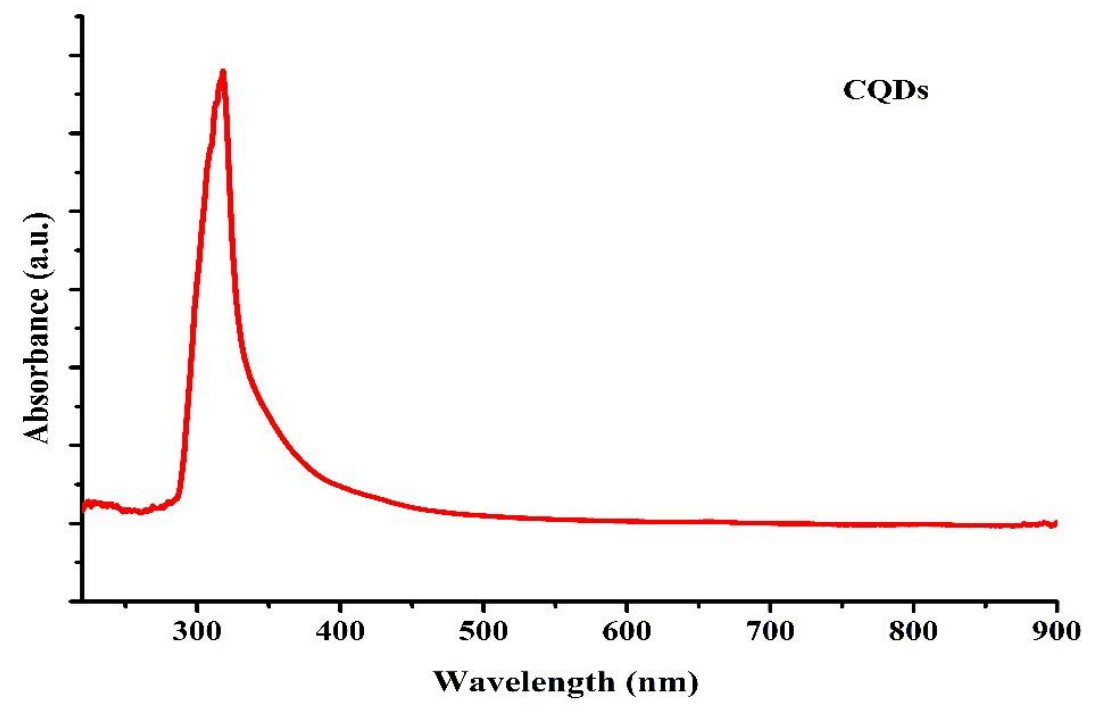

Figure 3: Absorbance spectrum of CQDs 


\subsection{Photocatalytic activity}

To evaluate the performance of photocatalytic activity under the irradiation of visible light, MO was used as target pollutant. As seen in Table 1 and Figure 4, the dye intensity from the MO solution decreased with the increment in irradiation time due to the degradation process. The dye removal process nearly achieved at $120 \mathrm{~min}$, with degradation rate of $68.9 \%$ which is an improvised result compared to previous study from Prasannan and Imae [16]. This result implied that CQDs can play a significant part in photocatalytic application based on the optical properties that show good absorption in the UV and up to near- visible region. Moreover, from the SEM and EDX analysis showing that CQDs synthesis through hydrothermal treatment possess a competent performance in which the presenting elements correspond to the major element that help in photocatalytic activity.

Table 1. Percentage of MO removal after 120 minutes photocatalytic activity was carried out

\begin{tabular}{|c|c|}
\hline Irradiation time (min) & $\begin{array}{c}\text { Percentage of MO Removal } \\
(\%)\end{array}$ \\
\hline Dark & 0.863 \\
\hline 0 & 0.84 \\
\hline 20 & 0.637 \\
\hline 40 & 0.464 \\
\hline 60 & 0.443 \\
\hline 80 & 0.308 \\
\hline 100 & 0.273 \\
\hline 120 & 0.268 \\
\hline
\end{tabular}

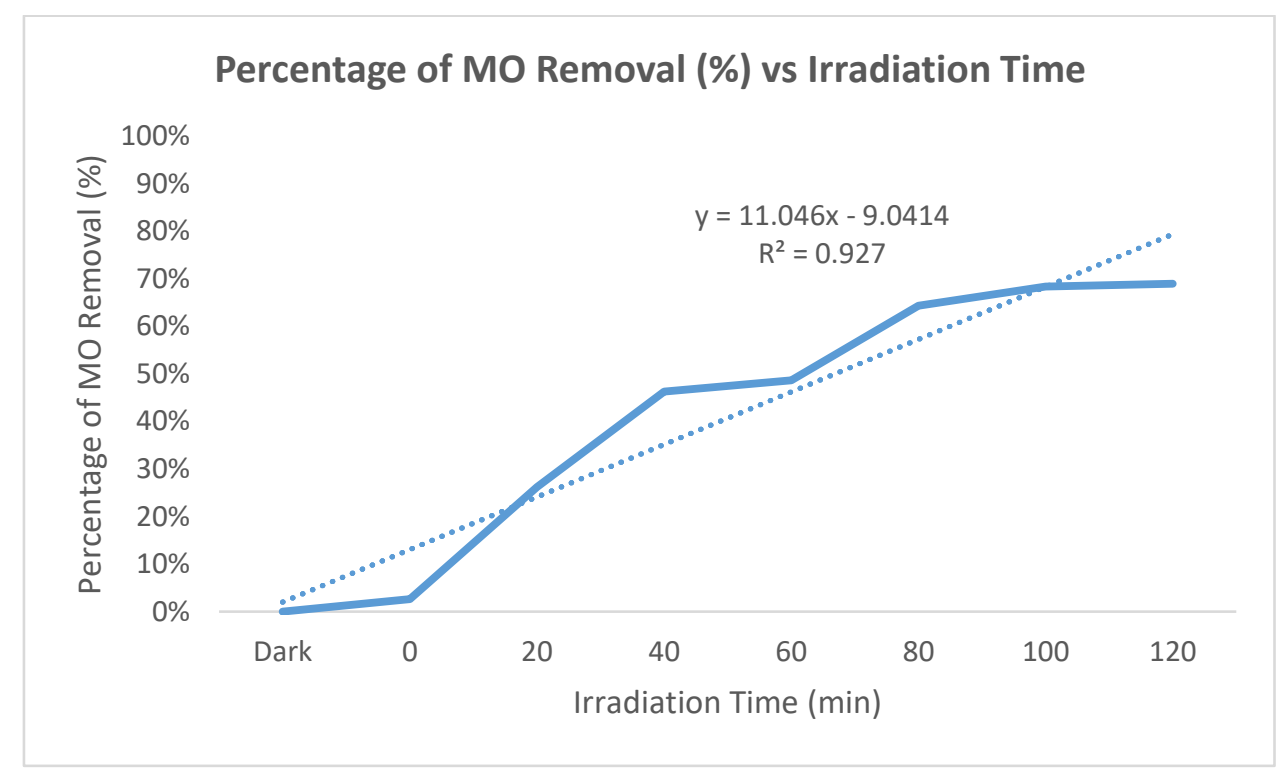

Figure 4: Percentage of MO removal at different time interval

\section{CONCLUSIONS}

In short, CQDs were successfully produced using the facile hydrothermal method from a readily available WMR as carbon precursor. Different characterizations analysis that has been conducted indicate the successful preparation of the CQDs with nanometer dimensions, with fascinating surface functional group that are useful in photocatalytic application. Finally, the prepared CQDs appealed to 
be sufficiently worthy of every recognition due to its value in green synthesis production, high solubility and have unique photoluminescence property that can enhance photocatalytic activity.

\section{ACKNOWLEDGEMENT}

The authors gratefully acknowledged UMP for financial assistance using Grant RDU 170120.

\section{REFERENCES}

[1] Ponnusamy SK., Anbalagan S, Vasudevan J. Prediction and interpretation of adsorption parameters for the sequestration of methylene blue dye from aqueous solution using microwave assisted corncob activated carbon. 2016; (December). Available at: DOI:10.1016/j.susmat.2016.11.001as

[2] E Misran*, O Bani EMS and ASP. Removal efficiency of methylene blue using activated carbon from waste banana stem: Study on $\mathrm{pH}$ influence ,2018. pp. 0-6. Available at: DOI:10.1088/1755-1315/122/1/012085

[3] Singla S., Kaushal J., Mahajan P. Removal of Dyes From Wastewater By Plant Waste. Advance Research in Science and Engineering. 2016; 5(03): 228-239. Available at: www.ijarse.com

[4] Fajriati I., Wahyuni ET. The Influence of $\mathrm{Cu}$ ( II ) on Methyl Orange and Methylene Blue Photodegradation Catalyzed by TiO 2 - Chitosan Nanocomposites. Journal of Advance in Chemical Engineering and Biological Sciences. 2014; 1(1). Available at: DOI:ISSN 23491507 EISSN 2349-1515

[5] Saravanan R., Gracia F., Stephen A. Nanocomposites for Visible Light-induced Photocatalysis.2017; : 19-41. Available at: DOI:10.1007/978-3-319-62446-4

[6] Fujishima A., Rao TN., Tryk DA. Titanium dioxide photocatalysis. Journal of Photochemistry and Photobiology C: Photochemistry Reviews. 2000; 1(1): 1-21. Available at: DOI:https://doi.org/10.1016/S1389-5567(00)00002-2

[7] Goryacheva IY., Sapelkin A V., Sukhorukov GB. Carbon nanodots: Mechanisms of photoluminescence and principles of application. TrAC - Trends in Analytical Chemistry. Elsevier Ltd; 2017; 90: 27-37. Available at: DOI:10.1016/j.trac.2017.02.012

[8] Wang Y., Hu A. Carbon quantum dots: Synthesis, properties and applications. Journal of Materials Chemistry C. Royal Society of Chemistry; 2014; 2(34): 6921-6939. Available at: DOI:10.1039/c4tc00988f

[9] Ke J., Li X., Zhao Q., Liu B., Liu S., Wang S. Upconversion carbon quantum dots as visible light responsive component for efficient enhancement of photocatalytic performance. Journal of Colloid and Interface Science. 2017; Available at: DOI:10.1016/j.jcis.2017.01.121

[10] Makama AB., Umar M., Saidu SA. CQD-Based Composites as Visible-Light Active Photocatalysts for Purification of Water. In: Yao Y (ed.) Visible-Light Photocatalysis of Carbon-Based Materials. Rijeka: IntechOpen; 2018. Available at: DOI:10.5772/intechopen.74245

[11] Sharma V., Tiwari P., Mobin SM. Sustainable carbon-dots: Recent advances in green carbon dots for sensing and bioimaging. Journal of Materials Chemistry B. Royal Society of Chemistry; 2017; 5(45): 8904-8924. Available at: DOI:10.1039/c7tb02484c

[12] Sun M., Ma X., Chen X., Sun Y., Cui X., Lin Y. A nanocomposite of carbon quantum dots andTiO2 nanotube arrays: Enhancing photoelectrochemical and photocatalytic properties. RSC Advances. 2014; Available at: DOI:10.1039/c3ra45474f

[13] Wang X., Cao L., Lu F., Meziani MJ., Li H., Qi G., et al. Photoinduced electron transfers with carbon dots. 2009; (25): 3774-3776. Available at: DOI:10.1039/b906252a

[14] Xu X., Ray R., Gu Y., Ploehn HJ., Gearheart L., Raker K., et al. Electrophoretic analysis and 
purification of fluorescent sing-walled carbon nanotube fragments. J. Am. Chem. Soc. 2004. pp. 12736-12737. Available at: DOI:10.1021/ja050082h

[15] Zhou J., Sheng Z., Han H., Zou M., Li C. Facile synthesis of fluorescent carbon dots using watermelon peel as a carbon source. Materials Letters. Elsevier B.V.; 2012; 66(1): 222-224. Available at: DOI:10.1016/j.matlet.2011.08.081

[16] Prasannan A., Imae T. One-pot synthesis of fluorescent carbon dots from orange waste peels. Industrial and Engineering Chemistry Research. 2013; 52(44): 15673-15678. Available at: DOI: $10.1021 / \mathrm{ie} 402421 \mathrm{~s}$

[17] Yu H., Zhang H., Huang H., Liu Y., Li H., Ming H., et al. ZnO/carbon quantum dots nanocomposites: one-step fabrication and superior photocatalytic ability for toxic gas degradation under visible light at room temperature. New J. Chem. The Royal Society of Chemistry; 2012; 36(4): 1031-1035. Available at: DOI:10.1039/C2NJ20959D

[18] Gong N., Wang H., Li S., Deng Y., Chen X., Ye L., et al. Microwave-Assisted Polyol Synthesis of Gadolinium-Doped Green Luminescent Carbon Dots as a Bimodal Nanoprobe. Langmuir. 2014; 30(36): 10933-10939. Available at: DOI:10.1021/la502705g

[19] Lim SY., Shen W., Gao Z. Carbon quantum dots and their applications. Chem. Soc. Rev. The Royal Society of Chemistry; 2015; 44(1): 362-381. Available at: DOI:10.1039/C4CS00269E

[20] Mehta VN., Jha S., Basu H., Singhal RK., Kailasa SK. One-step hydrothermal approach to fabricate carbon dots from apple juice for imaging of mycobacterium and fungal cells. Sensors and Actuators, B: Chemical. Elsevier B.V.; 2015; 213(July 2015): 434-443. Available at: DOI:10.1016/j.snb.2015.02.104

[21] Alam A-M., Liu Y., Park M., Park S-J., Kim H-Y. Preparation and characterization of optically transparent and photoluminescent electrospun nanofiber composed of carbon quantum dots and polyacrylonitrile blend with polyacrylic acid. Polymer. 2015; 59(Complete): 35-41. Available at: DOI:10.1016/j.polymer.2014.12.061

[22] Jhonsi MA. Carbon Quantum Dots for Bioimaging. State of the Art in Nano-bioimaging. 2018; Available at: DOI:10.5772/intechopen.72723

[23] Dimos K. Carbon quantum dots: Surface passivation and functionalization. Current Organic Chemistry. 2016; 20: 682-695. Available at: DOI:10.2174/1385272819666150730220948

[24] Jawad AH., Ngoh YS., Radzun KA. Utilization of watermelon ( Citrullus lanatus ) rinds as a natural low-cost biosorbent for adsorption of methylene blue: kinetic, equilibrium and thermodynamic studies. Journal of Taibah University for Science. Taylor \& Francis; 2018; 12(4): 371-381. Available at: DOI:10.1080/16583655.2018.1476206

[25] Jimoh A., Abdulkareem AS. Production of Activated Carbon from Watermelon Peel. International Journal of Scientific \& Engineering Research. 2014; 2(2). Available at: DOI:ISSN 2229-5518

[26] Maran JP., Sivakumar V., Thirugnanasambandham K., Sridhar R. Microwave assisted extraction of pectin from waste Citrullus lanatus fruit rinds. Carbohydrate Polymers. 2014; 101: 786-791. Available at: DOI:https://doi.org/10.1016/j.carbpol.2013.09.062

[27] Mushtaq M., Sultana B. RSM based optimized enzyme-assisted extraction of antioxidant phenolics from underutilized watermelon ( Citrullus lanatus) rind. 2015; 52(August): 50485056. Available at: DOI:10.1007/s13197-014-1562-9

[28] Ibrahim UK., Kamarrudin N., Suzihaque MUH., Abd Hashib S. Local Fruit Wastes as a Potential Source of Natural Antioxidant: An Overview. IOP Conference Series: Materials Science and Engineering. 2017; 206(1). Available at: DOI:10.1088/1757-899X/206/1/012040

[29] Ibrahim A., Yusof L., Beddu NS., Galasin N., Lee PY., Lee RNS., et al. Adsorption study of Ammonia Nitrogen by watermelon rind. IOP Conference Series: Earth and Environmental Science. 2016. Available at: DOI:10.1088/1755-1315/36/1/012020

[30] Treml J., Šmejkal K. Flavonoids as Potent Scavengers of Hydroxyl Radicals. Comprehensive Reviews in Food Science and Food Safety. 2016. Available at: DOI:10.1111/1541-4337.12204

[31] Turoti M.; Ogundana E.A. Journal of American Science 2017;13(11) Adsorption of Methylene 
blue dye from Aqueous solution Using Sodium Carbonate Activated. 2017; 13(11): 1-11. Available at: DOI:10.7537/marsjas 131117.01

[32] Lakshmipathy R., Sarada NC. Adsorptive removal of basic cationic dyes from aqueous solution by chemically protonated watermelon (Citrullus lanatus) rind biomass. Desalination and Water Treatment. 2014; Available at: DOI:10.1080/19443994.2013.812526

[33] Yu X., Liu J., Yu Y., Zuo S., Li B. Preparation and visible light photocatalytic activity of carbon quantum dots/TiO2 nanosheet composites. Carbon. Elsevier Ltd; 2014; 68: 718-724. Available at: DOI:10.1016/j.carbon.2013.11.053

[34] De B., Karak N. A green and facile approach for the synthesis of water soluble fluorescent carbon dots from banana juice. RSC Advances. 2013; 3(22): 8286-8290. Available at: DOI:10.1039/c3ra00088e

[35] Basavaiah K., Tadesse A., RamaDevi D., Hagos M., Battu G. Facile green synthesis of fluorescent carbon quantum dots from citrus lemon juice for live cell imaging. Asian Journal of Nanosciences and Materials. 2018; 1(Issue 1. pp. 1-51): 36-46. Available at: http://www.ajnanomat.com/article_57712.html

[36] Sachdev A., Gopinath P. Green synthesis of multifunctional carbon dots from coriander leaves and their potential application as antioxidants, sensors and bioimaging agents. Analyst. Royal Society of Chemistry; 2015; 140(12): 4260-4269. Available at: DOI:10.1039/c5an00454c

[37] Gedda G., Lee C-Y., Lin Y-C., Wu H. Green synthesis of carbon dots from prawn shells for highly selective and sensitive detection of copper ions. Sensors and Actuators B: Chemical. Elsevier B.V.; 2016; 224: 396-403. Available at: DOI:10.1016/j.snb.2015.09.065

[38] Kumar A., Chowdhuri AR., Laha D., Mahto TK., Karmakar P., Sahu SK. Green synthesis of carbon dots from Ocimum sanctum for effective fluorescent sensing of $\mathrm{Pb} 2+$ ions and live cell imaging. Sensors and Actuators, B: Chemical. Elsevier B.V.; 2017; 242: 679-686. Available at: DOI:10.1016/j.snb.2016.11.109

[39] Cong S., Zhao Z. Carbon Quantum Dots : A Component of Efficient Visible Photocatalysts Carbon Light Quantum Dots: A Component of Efficient Visible Light Photocatalysts. Available at: http://dx.doi.org/10.5772/intechopen.70801

[40] Alam AM., Park BY., Ghouri ZK., Park M., Kim HY. Synthesis of carbon quantum dots from cabbage with down- and up-conversion photoluminescence properties: Excellent imaging agent for biomedical applications. Green Chemistry. Royal Society of Chemistry; 2015; 17(7): 3791-3797. Available at: DOI:10.1039/c5gc00686d 